\title{
SOCIAL FACTORS IN THE DEVELOPMENT OF LEGAL CONTROL: A CASE STUDY OF TWO ISRAELI SETTLEMENTS
}

\author{
BICHARD D. SCHWARTZì
}

"The substance of every attempt to state the fundamental principles of the sociology of law [is that] the center of gravity of legal development lies not in legislation, nor in juristic science, nor in judicial decisions, but in society itself."

Ehrlich, Fundimental Principles of THE Socrology of LaW iw (1936)

Legal control is not exercised against all disturbing behavior. Sometimes, such behavior never reaches the courts. ${ }^{1}$ At other times, it is not sanctioned by the courts hecause, we are told, it should be left to "the intcrior forum, as the tribunal of conscience has been aptly called." The effects of non-legal or informal control, whether or not adequately described in terms of "conscience," seem to be an important factor in a court's decision to withhold sanction.

The relationship between legal and informal controls can be theoretically stated and empirically described. The cultures of two Israeli communities were compared in an effort to determine the social effects of economic collectivism. $^{3}$ One of the differences noted was that the collective community, or kvutza, had no distinctly legal institution, whereas the

$\doteqdot$ Instructor in Sociology, Yale College: Research Fellow in Behavior Scicnce, Institute of Human Relations, Yale University.

1. Professor Karl Llewellyn characterizes law as being concerned only with disputes "not otherwise settled." Llewellyn, Legal Tradition and Sincial Sicuce Mcthod-A Realist's Critinuc in Essays on Research in the Social Sciences $8 \%, 91$ (Broolings Institute 1931).

2. Mills v. Wyman, 20 Miss. 225, 3 Pick. 207 (1825).

"Without doubt there are great interests in sucitty which justity withholding the coercive arm of the law from these duties of imperfect obligation, as they are called; imperfect, not because they are less binding upon the conscience than those which are called perfect, but because the visdom of the social law does not impose sanctions upon them." Id. at 223, 3 Pick. at 210-11.

3. This work was carried out in 1949-50 with the aid of a Restarch Training Fellus: * ship from the Social Science Research Council and a Sterling Predoctoral Fellowship from Yale University. A full ethnographic report is presented in the author's I::STirurıo:all Consistency in a Coldective Soctety (unpublished thesis in Sterling Memorial Library, 1951).

4. For useful materials in English on Israel's collective communities, sce MALETz, Young Hearts (1950) (an account of a member's experience in a collcetive); bararz, Deganaa (1943) (description of the formative years of Israel's first brutza) lasn Yitsalsiar, The Kibbutz at the Crossroads 2 Zlonist Newsletren (Nos. 6-13, 1949-50). 
moshav, $\overline{5}$ a semi-private property settlement, did. Speculation on the reasons for the difference led to the formulation of a theory of legal control. The theory cannot be presented in detail in this article, ${ }^{8}$ but it will be used as a framework for the organization of the empirical data. While the data do not constitute empirical verification of the theory, ${ }^{7}$ it is hoped that the theory will help to explain the data, and the data serve to illustrate the theory.

In attempting to ascertain whether or not a social group has legal controls and, if it does, why these controls are applied to some but not to other forms of behavior, this article rests upon several assumptions:

1. For a given individual at a given time, some states of affairs are more satisfying ${ }^{8}$ than others.

2. A gain in satisfaction is defined as transition from a less to a more satisfying state of affairs; a loss of satisfaction is the reverse; an indifferemt experience as no change in satisfaction.

3. The frequency, vigor, and speed with which an action is performed in a given situation is an increasing function ${ }^{\circ}$ of the degree (frequency, magnitude, and immediacy) to which similar behavior has previously been followed by gain, and of the extent of similarity perceived by the present actor between the present behavior and behavior previously followed by gain. Conversely, the frequency, vigor, and speed with which an action is performed in a given situation is a decreasing function of the degree of gain following competing (alternative and incompatible) behavior, and of the extent of similarity perceived by the present actor between present competing behavior and similar behavior previously followed by gain.

These postulates are stated in general terms because it is purposed to apply them to the behavior of all participants in the process of social control. Social control involves interaction, i.c., behavior on the part of one actor which affects the behavior of another. Control is distinguished from other forms of interaction in that it includes sanction, i.e., the administration of gain or loss to an

5. For some of the few English sources available on the moshav, see DAYAN, Mosilav Ovdix (1947); Messinger, Kvutzah Moshav Krbbutz (1949).

6. The detailed theory, on file in the Institute of Human Relations, Yale University, was developed in connection with the Institute's Postdoctoral Program in Behavior Science, under the directorship of Mark A. May. See Hull, Essentials of Benuvion (1951), for the postulates which provided the starting point for this theory.

7. For verification, this theory should be tested against data which did not contribute to its formulation, and which are more extensive than those presented here.

8. Many methods have been proposed for the measurement of relative satisfaction, among them verbal reports, decisions of experts, and physiological indices. We would prefer to let the definition rest ultimately on choice behavior. When an individual is given the choice between two states of affairs after having fully experienced both, the one which he selects is defined as more satisfying for him. If verbal or other measures are found to be correlated with such choices under certain circumstances, they may be substituted for purposes of convenience.

9. For " $\mathrm{X}$ is an increasing function of $\mathrm{Y}$," read, "Other factors equal, as $\mathrm{Y}$ increases, $\mathrm{X}$ increases." 
actor. Sanction is positive when it results in gain for the sanctionee, and negative when it results in loss.

From our assumptions it can be deduced that a sanctioner tends to employ positive sanctions following any behavior $(x)$ which is typically gainiul to him. If positive sanction occurs after $x$, the likelihood is increased that under similar circumstances $x$ will be repeated vigorously and speedily. If $x$ continues to be gainful to the sanctioner, his tendency to respond to it with positive sanction is reinforced.

In the same way it follows that negative sanction tends to be employed following behavior $(y)$ which typically results in loss for the sanctioner. Imposition of negative sanction following the performance of $y$ decreases the gain which its performer may have obtained by it and increases the likelihoor that he will gain by switching from it to some incompatible behavior. If, as a result, the actor performs $y$ less often and less vigorously, the sanctioner experiences a gain because there is a transition from a less to a more satisfying state of affairs. Therefore his tendency to respond to $y$ with negative sanction is increased.

Other factors also affect the likelihood that a given sanction will recur. The impact of a sanction may be supplemented or reduced by collateral gains and losses experienced by the sanctionee. Even if, as a result of all these influences, sanctionee's behavior is modified in a way gainful to the sanctioner, the gainful effect need not reinforce the sanction; it can be offset by collateral luszes experienced by the sanctioner. Important among these are any experiences which have strengthened the tendency of the potential sanctioner to respond in a competing way either by employing a different sanction or by exerting no sanction at all. The greater the tendency to perform such competing reactions, the less is the likelihood that the given sanction will be employed.

In the interactive aggregates of individuals which we call social groups, two main forms of control may be distinguished: that which is carried out by specialized functionaries who are socially delegated the task of intra-group control, and that which is not so delegated. These will be respectively designated legal and informal controls. When, as is often the case, these two forms of control are in competition, the likelihood of legal control arising at all in a given sphere is a decreasing function of the effectiveness of informal controls. It is the thesis of this article that the presence of legal controls in the moshav, the semi-private property settlement, but not in the kvutza, the collective settlement, is to be understood primarily in terms of the fact that informal controls did not operate as effectively in the moshav as in the kvutza.

\section{Control Systens in the KuUtza and Moshay}

In most of their superficial characteristics, the two settlements are essentially similar. Both were founded at the same time, 1921, by young settlers who had come from Eastern Europe "to build a new life." Though the lvutza was smaller at first, it has grown to a population (just under 503 persons) which 
is almost identical in size with that of the moshav. Both are located on a slope of the Jezreel Valley where they have to deal with the same climate and similar topography. Both have about two thousand acres of land, which supports a mixed farming economy. Both populations have rejected many of the East-European Jewish customs, including traditional religious practices. Though many other Israeli collectives are left-wing socialist, the members of the kvutza under consideration resemble those of the moshav in adhering to the social-democratic political philosophy represented by the Mapai party.

Despite these similarities, the two communties have differed from the outset in their members' ideas about economic organization. In the kvutza, members felt they could implement the program, "from each according to his abilities, to each according to his need," as the way to create a "just society." Moshav members, many of whom had spent a few years in collectives, decided that the family should be the unit of production and distribution, and that thus a class of small independent farmers could be developed in the moshav which would provide a strong agricultural base for the country.

As far as could be ascertained, there were no initial differences in specific ideas concerning legal control. Legal jurisdiction over crimes and civil wrongs is recognized by all to reside in the State of Israel, but very few cases involving members of these settlements have been brought before the State's courts or, earlier, before the courts of the British Mandate. The minimal role of these courts has resulted from an absence of serious crime; the shielding of fellow members from British (and now to a lesser extent even Israeli) "outsiders": and internal controls which effectively handle existing disturbances. In both settlements, the power to exercise these internal controls stems from the General Assembly, a regularly held meeting of all members in which each one present casts a single vote. This form of government works effectively in both communities, perhaps because they are small enough for everyone to be heard and homogeneous enough so that there is basic agrecment on means and ends. While the kvutza meetings are more frequent and cover a broader range of issues, moshav sessions are held at least bi-weekly and are generally well attended.

In both settlements, the General Assembly delegates responsibility for certain activities to committees whose membership it approves. Committees are, if anything, more active in the kvutza, which has separate permanent groups to deal with questions of economic coordination, work assignment, education, social affairs, ceremonies, housing, community planning, and health. The moshav also has its committees, but most of these deal with agricultural matters, particularly the dissemination to individual farmers of the kind of scientific information which is handled by managers in the kvutza.

The moshav's Judicial Committee, however, is a specialized agency for which no counterpart is found in the kvutza. This Committee consists of a panel of seven members elected annually by the General Assembly for the purpose of dealing with internal disputes. Complaints by members against members are brought before the Committee either directly or by referral from 
the General Assembly. A hearing of the complaint is then conducted by a panel of three drawn from the larger Committee. After investigating the circumstances and hearing the direct testimony of both sides, a panel decides whether and how the defendant should bear responsibility. Fines and damages, the major types of punishment, are usually paid upon imposition, but if not, they are enforceable by the secretary of the moshav. Though these panels follow simple procedures, there can be no doubt that they have acted as an agency of legal control in the moshav.

An example will illustrate the operation of this moshav system of legal control. A fifteen-year-old boy took a neighbor's jeep without nermission. picked up some of his friends, and went for a joyride outside the village. During the ride, he crashed into a tree and damaged the fender and door of the vehicle. The owner brought a complaint against him which was heard by the panel. When the boy admitted his actions, he was charged for the full cost of repairs. The debt was subsequently discharged by the boy's parents. and the case was considered closed.

By contrast, the kvutza has not delegated sanctioning responsibility to any special unit. Even when administrative or legislative action results in gain or loss to an individual, this is not its primary purpose. In the event of a dispute between workers, for example, the Work Assignment Committee or the Economic Council may decide that the interests of production would be better served if one or both of the workers were transferred. But the objective of such action is not punitive; rather it is to ensure the smooth functioning of the economy, and the decision is made in much the same manner as any decision relating to production.

In the course of its legislative work, the General Assembly of the kvutza also makes decisions which modify the gains and losses of members. Mlany of these are policy decisions which apply to classes of members, but sometimes an individual's behavior provides the occasion for a policy debate in the Assembly. One young member, for example, received an electric teakettle as a gift from his sister in the city. Though small gifts could be retained as personal property, the kettle represented a substantial item, and one which would draw upon the limited supply of electricity available to the entire settlement. Moreover, the kvutza had already decided against supplying each room with a kettle on the grounds that this would be expensive and would encourage socially divisive private get-togethers. By retaining the kettle, therefore, the young man was threatening the principles of material equality and social solidarity on which the kvutza is believed to rest. This at any rate was the decision of the Assembly majority following three meetings during which the issue was debated. Confronted with this decision, the owner bowed to the general will by turning his teakettle over to the infirmary where it would be used by those presumed to be in greatest need of it. No organized enforcement of the decision was threatened, but had he disregarded the expressed will of the community, his life in the kvutza would have been made intolerable by the antagonism of public opinion. 
As will become apparent, it is the powerful force of public opinion which is the major sanction of the entire kvutza control system. It may be foctised, as in the case of the electric teakettle, by an Assembly decision, or it may, as occurs more commonly, be aroused directly by the behavior it sanctions. In either case, it is an instrument of control which is employed not by any specialized functionaries but by the community as a whole. Since public opinion is the sanction for the entire kvutza control system, that system must be considered informal rather than legal. We turn now to a more detailed consideration of the factors which have made this system of control so much more effective in the kvutza than in the moshav.

\section{SANCTION IMPACT}

From our assumptions, we may deduce that the extent to which a sanction, legal or informal, modifies the tendency of given behavior is a function of the frequency, magnitude, and immediacy with which it follows the sanctioned behavior. Frequency of sanction depends on the number of times the behavior is performed, the proportion of times its performance is observed by potential sanctioners, the proportion of observations which evoke a reaction, and the proportion of reactions which actually have a sanctioning effect. For any given instance of sanction, magnitude of sanction depends on the vigor of reaction, the extent to which the reaction is implemented, and the average gain or loss to the sanctionee per unit of experienced sanction. For example, magnitude of sanction resulting from a fine would depend on how many dollars were demanded (vigor), how many of these were collected (implementation), and how great a loss each dollar constituted for the payer. Immediacy of sanction is a function of how soon after its performance the pertinent behavior is perceived by the sanctioner, how speedily he reacts to it, and how quickly the reaction is experienced by the sanctionee. It follows from all this that sanction impact is an increasing function of the numbers of potential sanctioners who perceive or are informed of the pertinent behavior, and of the accuracy, frequency, and speed with which this information is obtained; an increasing function of the capacity of informed would-be sanctioners to implement their reactions; an increasing function of the magnitude of gain or loss which that reaction, once implemented, imposes on the sanctionee; and an increasing function of the extent to which potential sanctionees perceive and therefore vicariously learn from the experience of sanctionees.

\section{Information:}

For the control of any behavior which would, if known, be effectively sanctioned, it is important that potential sanctioners know accurately and quickly of its occurrence. Accuracy implies that the behavior comes to the attention of the reactors as often as possible and that they know who has done what, under which conditions. Each time such behavior is known to have occurred, reactors gain an opportunity to increase the frequency of sanction. 
The more quickly this information is obtained, the greater is the immediacy with which sanction can be administered.

Accuracy and speed of perception tend to be high in what Cooley has described as the "primary group," characterized by "intimate face-to-face assuciation and cooperation."10 Though such groups are typically small in size, we shall see that under certain conditions a high frequency of face-to-face associatiun or interaction can occur in groups as large as the krutza. Cooley gues on to hypothesize of primary groups that they are "fundamental in forming the rocial nature and ideals of the individual," which is close to saying that they are characterized by effective systems of control. ${ }^{11}$ Though there is little trustwurthy evidence on this point, ${ }^{12}$ it seems plausible in light of the propositions that accurate information is a prerequisite to control and that the face-to-face intimacy of the primary group makes such information possible.

The kvutza is in effect a large primary group whose members engage in continuous face-to-face interaction. Each able-bodied member works eight to ten hours a day, six days a week, at a job which is usually performed wholly or partially in the presence of others. The results of his efforts become known to his associates, the work manager, and the top officials who coordinate the economy. All three meals are eaten in a collective dining hall usually in the company of five other residents who happen to have arrived at the same time. Members of each sex share common washing and shower facilities, and these are used by most members at the same time, during the limited period when hot water is available. Housing is concentrated in one area of the kvutza and consists of rows of long houses, each partitioned to make six rooms, with a married couple or two roommates occupying each room. Because most roums are surrounded by other dwellings, it is easily possible for neighbors to observe entrances and exits and even some behavior within. Child rearing is the primary responsibility of special nurses and teachers, but parents spend about two hours with their children on work days and usually more than this on their days of rest. Much of this relationship is subject to public view as parents and children stroll around the kvutza, eat together occasionally in the dining hall, or play in front of their rooms. Other leisure activities are also subject to public observation: participating in Assembly and Committee meetings, celebrating kvutza holidays, attending lectures and films, perusing news-

10. Cooley, Sactal Organization 23 (1909). See also Clow, Cooley's Doefrine of Primary Groups, 25 A.r. J. Sos. 326 (1919). For a recent discussion, see Shils, The Study of the Primary Group in THe Policr Scrences 23-31 (Lerner \& Lasswell eds. 1951). Shils prefers to base his definition on characteristics of group culture rather than un mure easily described characteristics such as size.

11. Cooley, Soclal Organization 23 (1909).

12. Psychoanalytically oriented studies, c.g., Karmenes, The Psregolocicul. Frus:tIERs of Society (1945), and "foll society" research, c.g., Renfieln, Tue Folk Culture. of YUCATAN (1941), introduce variables, respectively, of primacy of training and rapidity of cultural change which, for our purposes, are extraneous. For a sepresentative experimental study of small group controls, see Asch, Effects of Group Pressure on the Modification and Distortion of Judgments in Grot'ps, LEubersint AND Mie: (Guetzliow ed. 1951). 
papers and periodicals in the kvutza reading room, or taking a vacation tour of the country. Even sexual relations, particularly if they are illicit, can become the subject of general public knowledge, although this was the one type of activity excepted by a member when he said, "amongst us, all things except one are done together."

The same conditions of continuous interaction also make it possible to circulate information throughout the entire community. Mealtime and showering are two informal occasions when large numbers of people forgather and find opportunity for conversation. The shower in particular is a forum for the transmission of information where one can hear about anything from fractured ankles to broken hearts. Though "I heard it in the shower" is a kvutza equivalent for "take this with a grain of salt," much genuine news is clisseminated there. Compared with these informal techniques, the weekly news bulletin and the Assembly meetings run slow supplementary seconds.

Moshav conditions do not permit as great a degree of public observation. Work is typically conducted alone, with other members of the family, or occasionally with the voluntary aid of a friend. As long as the moshav farmer maintains a solvent establishment and discharges such community obligations as payment of taxes and correct use of cooperative facilities, he is free to manage his farm as he sees fit. Meals consisting largely of produce from the farmstead are prepared by the housewife and eaten in a family dining room which occupies a central place in the home. Houses are snall bungalows ranging from three to six rooms, separated from neighboring dwellings by a hundred yards or more, and screened by hedges and fruit trees. Many activities which are publicly performed in the kvutza can be, and usually are, carried out in the privacy of the moshav home, among them economic husbandry, care of clothing, showering, washing, child rearing, and such recreation as visiting, reading, and listening to the radio. There are, to be sure, places where members come into contact, such as the produce depots, cooperative store, Assembly and committee meetings, and cinema. Though such contacts provide some opportunities for the circulation of information, they are fewer and the information circulated is less complete than in the kvitza.

At least partially as a result of these differences, kvutza members do in fact learn more about the activities of more of their members than is known in the moshav. Less than a week of residence was necessary in the kvutza before virtually everyone knew the ostensible purpose of the writer's stay, whereas similar knowledge was not diffused as widely (or accurately) during two months in the moshav. Information thus transmitted is not confined to work performance and consumption, though these are of great interest, but range over such details as mail received, visitors contacted, time spent with chilktren, and even style of underclothes worn. As a result, it becomes possible to control types of behavior in the kvutza which never become public knowledge in the moshav.

Since we are primarily interested in the effects of such factors as information status on the development of legal controls, it is unnecessary for our 
purposes to analyze in detail the reasons for these differences. It should be noted, however, that krutza intimacy was not solely the result of conscious planning concerning social relations. Though the desire for intimacy was a factor, it was strongly supplemented by other pressures, such as those arising as unanticipated by-products of the need for economic efficiency in a collective economy.

\section{Implementation:}

If it is important for effective control that the behavior in question be perceived by reactors, it is at least as necessary that their sanctions be perceived by sanctionees. Though a reactor may behave in a way which tends to exert sanction, this reaction cannot achieve maximum control over behavior unless it is experienced by someone who could be sanctioned by it. Uncollected damages and unserved jail sentences are presumably not as effective in controlling negligent or criminal behavior as are implemented judgments. Similarly, in the operation of informal control, the failure of sanction implementation constitutes a major reason for the apparently deviant behavior of such transient individuals as traveling salesmen, hoboes, railroad workers, and hutel guests. ${ }^{13}$

Conditions necessary for the implementation of a sanction depend on the nature of the sanction. The implementation of public opinion-major informal sanction in the Israeli settlements-requires that public approval or disapproval be accurately and speedily communicated to sanctionees. This is accomplished in the krutza by essentially the same conditions as made the perception of behavior so readily possible, namely, the continuous interaction characteristic of the primary group. In the case of implementation, the interactive process is simply reversed, with sanctioners providing the action which is then perceived by sanctionees.

Public opinion can be manifested often, swiftly, subtly, and with varying degrees of intensity in the kvutza. In the course of a day's continual interaction, positive or negative opinion may be communicated by the ways in which members glance at an individual, speak to him, pass him a requested work implement or dish of food, assign him work, give him instructions, sit next to him, and listen to his comments. To an experienced memlser, these small signs serve to predict more intense reactions of public acclaim or social isolation. They therefore acquire sanctioning power in and of themselves and become able to control the behavior in question before extremes are reached. In the moshav, by contrast, there are fewer opportunities to convey public opinion quickly and accurately because there is so much less contact between members in the course of the daily regime. This is an impurtant limitation in the use of public opinion as a means of contrul in the moshav.

13. Some evidence on these points will be found in Burgess \& Cortacte, Promintivis

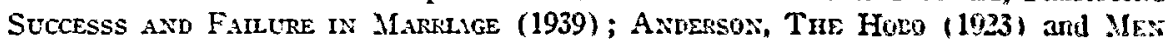

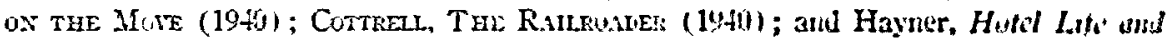
Personality, 33 Ax. J. Soc. 784 (1928). 


\section{Magnitude of gain or loss:}

In order for public opinion to be effective, it is important not only that changes in it be perceived but that these be capable of providing gain or loss to the sanctionee. If he is indifferent to public opinion, his behavior will not be directly changed by such sanction. If, on the other hand, he is "otherdirected," so that modification in public attitude involves relatively greater" loss or gain to him, we would expect him to be effectively sanctioned by public opinion. ${ }^{14}$ As a whole, the population of the kvutza is far more concerned with public opinion than is that of the moshav. Several factors appear to have contributed to this characteristic, among them differences in immigration, emigration, child training and adult experience.

Since these settlements were studied thirty years after they were founded, it is difficult to know whether immigrants were different at the outset. It is possible that people to whom public opinion was important may have gravitated to the collective type of community, or at least that those who stayed were particularly responsive to it. Looking back at their primary reasons for coming, almost three out of four present kvutza members refer to socially oriented motives, e.g., social solidarity, building a just society, changing human nature. Such motives were said to be primary by only one-third of the present moshav members. Many of the moshav members emphasized economically oriented motives, e.g., strengthening the country as a whole or their own economic position in particular.

The effect of this self-selection process may have been aided to some extent by a kvutza policy of admitting to permanent membership those candidates who receive a majority vote after a trial period ranging from six months to a year. In the early years particularly, potential members were carefully scrutinized for the characteristics which were thought to make good kvutza material. For a new person to appear to be a good worker and a harmonious comrade, it was necessary that he respond to public opinion. This ability is still tested in many subtle ways. Candidates for membership are not explicitly told all the ways of the kvutza and must learn many of them through the informal control system. In the dining hall, for example, new residents are not instructed in the complicated standards governing substitution of desired food for allotted dishes. They must learn, mainly by observing others, which kinds of foods can or cannot be taken from the waiter's cart in exchange for a dish which has already been served. Speed of learning is noted by the old-timers, and failure to learn over an extended period contributes to a negative impres: sion of the candidate. Oftentimes individuals who fail to meet such tests are subjected to social disapproval which is sufficiently unpleasant to cause their emigration from the settlement. In general the emigration rate has been higher from the kvutza than from the moshav, and it is presumed that those who have left have been less able to conform to public opinion than those who have remained.

14. Stemming from Freud through Fromm, this distinction has been given recent expression in Riesman, The Lonely Crowd (1950). 
By contrast, no such elaborate procedures are used to determine fitness for moshav members. Most of the available farmsteads were talien years ago by the families which still occupy them. Emigration is based primarily on inability to make a success of farming, but it is doulstul whether sensitivity to public opinion enhances or decreases the chances of success. Since a farmings tradition has not yet been established, success often comes to the viry inlivilual who flouts public opinion and proceeds in accordance with his uwn notionn. New families are accepted primarily on the basis of their promise as succes-ful farmers and secondarily on their apparent conformity to social requirements.

Far less wasteful for the kvutza than a continuous circulation of personnel would be a system of training to increase responsiveness to public opinion. Krutza child training practices seem to produce this effect. Children are raised from infancy in the constant company of other children of their own age with whom they sleep, eat, bathe. dress, play, and later attend school. Though control is at first the task of the nurses, it is increasingly taken over by the children themselves. Their community is organized politically in a manner similar to the adult kvutza, with children's public opinion playing a corresponding part. When one child was caught stealing bananas reserved for the babies, the Children's Assembly decided to punish the culprit by abrogating their own morie privileges. Though this was explained to the adults on the grounds that all were involved in the guilt of one, a reason of at least e'!ual importance was the children's expectation that this reaction would provide such a loss to all the children that a potential wrongdoer would repeat the precipitating action at his peril. At any rate, the practice of stealing was greatly reduced following this reaction.

During their years of training. the krutza children become very alert to their peers' opinions, on which they are dependent for virtually all their satisfactions. While they are growing up, this force is used to ensure conformity to the standards of the children's community. These standards may conflict with those of the adult community, resulting in beharior which seems wild and capricious to the adults. But adult members remark repentedly on the suddenness with which, following their accession to formal membership at eighteen. children of the kvutza "mature," i.c., learn to conform to adult standards. This is in contrast to the moshav where adolescence is a period of great stress extending over several years. Moshav children, brought up in the close-knit farm family under their parents' control, never seem to develop the great respect for public opinion characteristic of the krutza. ${ }^{15}$

Supplementing migration and socialization practices are the day-to-day experiences of adult kvutza members. Quick and accurate response to public opinion enables the member to align his behavior with community standards. and thus to enhance his chances of attaining the acceptance and prestige which

15. For a detailed comparison of socialization practices in these types of settlements, see Eisexstadt. Age Grocps and Social. Structurf. (mimeomraphed in Ierusalem, 1951). 
are needed for even small advantages. In the kvutza environment, one is rewarded for responding to the unfavorable reaction of his comrades when he talks too long in the Assembly, does not volunteer for emergency work service, wears inappropriate clothes, or debunks a kvutza celebration. Failure to respond has been known to result in serious difficulties, stch as that experienced by a teacher who so antagonized public opininon by declining to dig trenches during Israel's War of Independence that he was denied a requested change of job a full year later.

In the moshav, this kind of pressure is exerted less frequently and effective$1 y$, if for no other reason than that there are fewer gains for which the individual is dependent on the community. Near self-sufficiency in economic affairs makes it difficult for the moshav to exert informal control. Primary reliance is placed on sanctions such as fines or, in a few cases of economic failure, expulsion from the settlement.

Thus several factors appear to contribute to the relatively greater power exercised by public opinion in the kvutza. It is difficult to estimate the effects of each of these in the absence of accurate knowledge concerning the values of immigrants and emigrants, as well as changes in the values of present residents since their time of settlement. Nevertheless, processes of selection, child training and adult experience were at work which might well be expected to result in kvutza members being more sensitive to public opinion than were moshav members.

This expectation is confirmed in the verbal reports of the members themselves. A sample of adult members in both settlements were asked whether in the event of clash between their own views and the demands of public opinion they behaved in accordance with the former or the latter. Only onethird of the kvutza respondents said they would follow their own inclinations in such a case, while almost three-fifths of the moshav members said they would. Such a difference would have occurred by chance so infrequently that we are justified in considering it statistically significant. ${ }^{10}$ These quantitative data provide confirmation of differences which had already been observed by ethnographic methods.

16. Behavior in the Event of Conflict

\begin{tabular}{|c|c|c|c|c|}
\hline \multicolumn{4}{|c|}{ Kvutza } & Moshav \\
\hline & $N$ & $\%$ & $N$ & \\
\hline Follow own inclinations & 36 & 33 & 87 & 5 \\
\hline Hlow pu & 74 & 67 & 65 & \\
\hline Total & 110 & 100 & 152 & \\
\hline
\end{tabular}

Four questions were asked, comprising a "Guttman scale." For a detailed description of this method see MEasurement and Predicrion (Stouffer, ed. 1950). The writer had the benefit of Dr. Guttman's advice in the construction, pretesting, and administration of this scale. A ninety percent sample was obtained of the adult members, but only threcfourths of these answered all the questions on this scale. Though some sample bias may have resulted from these opinions, it would have to be extreme in order to invalidate these results. 


\section{Vicarious Learning:}

If the effects of sanction were confined to the behavior of sanctionees, social control would be very difficult. Because people are alle to learn from the experience of others, however, the control process is greatly facilitated. Such experience has been discussed in several disciplines, ranging from psychoanalytic theories on "identification" to jurisprudential discussions of deterrence. A definitive answer has yet to be found to the very important question as to who vicariously learns what from the observed experience of whom.

Our theoretical orientation suggests that vicarious learning depends on the extent to which an observer perceives himself similar to an observed actor. As perceived similarity increases, so also does the likelihood that the observer will have his tendencies increased for behavior which the actor has gainfully: performed. At least two factors would thus appear requisite to vicarious learning: the observer must know of the behavior of another and its consequences, and he must perceive that actor as somewhat similar to himself.

In the kvutza, both of these conditions for vicarious learning are fulfilled to a very great degree within the informal control system. Intimacy in the kvutza, as noted, permits extensive observation of other members' experiences. Moreover, there is considerable evidence that krutza members perceive themselves as "comrades" in a homogeneous group. Their perception of similarity may well be enhanced by the mere physical resemblance among members. Men are issued the same kind of clothes, and women wear rather similar ones; even their haircuts are given without much variation by one barber why visits the kvutza. But such factors only supplement the more basic similarities of life conditions, including work schedule, consumption, and leisure activities. In all of these, members are subject to fairly uniform controls, so that they experience gain when they consider themselves similar enough to their fellow members to learn from their experiences. These factors contribute to a strong "we" feeling, one of whose effects may well be to heighten vicarious learning in the kvutza. This feeling is not challenged, as in the moshav, by the distinctive customs of individual families.

The difference between the two settlements is reflected in the responses of the members when asked to construe the phrase "amongst us."17 Ninety-five percent of the responding kvutza members stated that they referred to their entire community when they used this term. By contrast, more than half of all moshav respondents used the term in application to their families and fewer than a third used it to refer to the entire settlement. The kvutza thus appears to provide more of a "reference group"1s for its members than does the moshav. ${ }^{19}$

17. Ninety percent of the adult members of both communities were sampled, and over eighty percent of the polled members responded to this question.

18. See the discussion of this concept by Merton \& Fitt in Costr:itmes I: Sucul Research, I: Studies in the Scope and Miethod of "The AnericnN Soldies" 40 (Merton \& Lazarsfeld eds. 1950).

19. Of 124 kvutza respondents, 118 used the term to refer to the entire community. 
This orientation sets kvutza members apart from the outside world, even from members of other collective settlements. This was reflected by the children of the settlement in holding themselves aloof from the children of other collectives, reminding each other, "We are from 'Orah.' "20 In general, the attitude toward outsiders is one of sharper differentiation than is found in the moshav. This was manifested in the carefully correct or even suspicious manner in which kvutza members reacted to strangers, especially foreigners and Arabs, as against the tendency of moshav members to invite sttch persons into their homes.

\section{NORMS}

Every system of control consists of more than the simple ability to apply sanctions. In order to maximize their gain, reactors must know whether and how to react to different behaviors. By denoting given behavior as similar to a class of behaviors, reactors tend to evoke from themselves and from others the same reaction to the particular behavior as has been learned to the class. ${ }^{21}$ Such a classification will tend to result in gain if the reaction to the class results in maximal gain, and if the particular behavior resembles the class in its social consequences (i.e., both cause gain or both cause loss), and if the learned reaction to the class affects the tendency of the given behavior as it does the class.

The effectiveness of kvutza informal controls is enhanced by a system of norms classifying all behavior with reference to desirability. This system is detailed, generally unambiguous, applicable to wide, clearly defined segments of the population, and well known to the members. As a result it provides consistent guides for the application of sanction and at the same time forewarns potential sanctionees of the consequences of their acts. Such norms, found in every sphere of kvutza life, are particularly striking in economic matters.

Work activities in the kvutza are directed toward maximizing the production of agricultural goods and the performance of domestic services. Each able-bodied adult resident is expected to work in some unit, either an agricultural branch (e.g., orchard, poultry, or sheep) or a domestic service (e.g., kitchen, laundry, or school). Labor allocations are made by a Work Assignment Committee on the basis of economic requirements of each unit, ability of workers to meet those requirements, and lastly the preferences of each worker. Workers learn of their assignments either orally or by notice posted on the bulletin board. This assignment is understood to mean, unless otherwise specified, that the worker will report to the manager of the given unit

Only 49 of 157 moshav respondents used it in this way. $\mathrm{X}^{2}=117.49 ; \mathrm{P}<.001$. Thesc differences would have occurred by chance less than one time in a thousand.

20. "Orah" is a fictitious name which has been substituted for the real name of the kvutza studied in order to preserve the anonymity of the members.

21. See the discussion of legal "reasoning by example" in LEVI, $\Lambda N$ INTRont(TION 10 Legal Reasoning (1949). 
within a reasonable time (about fifteen minutes) after the morning bell has rung, and work there, except for brealfast. lunch, and siesta, until the evening bell signals the end of the working day. Some assignments (c.ll. nursery, dairy, trucking, and night watch) require special hours, but these are explicitly stated and the krutza assigns a functionary to rouse such workers and notify them of the start of their workday. Illness constitutes the major reason for exemption from this norm, and all sick persons are expected to consult the resident community physician who decides whether and for how ling tise patient is to abstain from work.

Each worker is expected to cooperate with the individual recognized by all as the coordinator or manager of his unit. Usually such recognition in relatively spontaneous, based upon superior knowledge, skill, leadership ability, and seniority. When no single individual is clearly superior in these reacrit. the Economic Council recommends reassignments which bring ahout this sesult. As a consequence, the worker typically has someone to whom he turn for guidance whenever he is uncertain as to the correct course of action. On their part, managers, though exercising considerable diseretion, are expected to turn to the Economic Council for guidance in significant decisions. Ultimately, the Council itself is responsible to the General Assembly. Ill kruza members are expected to perform their various activities to the best of their individual abilities. These abilities are recognized to vary widely, but kvutza members maintain that a certain level of performance exists for each worker in a given kind of job. Though a worker's prestige varies with the height of this level, he may be well esteemed if he consistently meets even a low standard of performance. Since the level of performance is set by the worker's better performances, he is likely to be considered a violator of this very significant norm if he is erratic and frequently falls below his standari. In an economy which has abolished wages and private profit, these work norm. are of great importance in maintaining production.

Consumption activities in the kvutza are also controlled with the aid of explicit general norms. Objectives which these are supposed to serve include distribution according to need, frugality, solidarity, and of course adequate sustenance of the population. Since differential need is very difficult to ascertain, the kvutza tendency has been to distribute scarce items equally, on the assumption that need is generally equal. Exceptions are made in instances where this is obviously not the case, for example, when youth, age, illness, or pregnancy furnishes grounds for special diet, housing, or medical care. Aside from these, however, consumption of scarce goods is supposed to be as nearly equal as possible. Adults are expected to eat together in the common dining hall at specified times. There they are served meals which are planned by the dietician with an eye toward fitting the budget adopted by the General Assembly. Crops drawn directly from the land are usually sufficiently abundant to permit unrestricted consumption, but other foods such as margarine, fish, meat, hard cheese, and eggs are distributed in limited equal quantities. Though the norms governing such consumption may be a mystery to new 
arrivals, members are fully aware of them. Occasionally questions arise as to the kinds of dishes for which a given serving may be exchanged, but these are authoritatively settled by the dietician. Similarly, clothes are expected to be issued equally except for differences of sex and size. Women are permitted a small degree of discretion in the selection of materials, but no one may exceed the ration and standard for a given sex, of such items as work shirts, work shoes, and sweaters. In housing, correct behavior is even less complicated: one is expected to live in the room assigned by the Housing Conmittee, whose discretion is limited by policies established in the General Assembly. Explicit general norms also cover such matters as participation in kvutza festivals, visiting of children by parents, and preservation of a minimal privacy in rooms.

Such a pervasive set of general norms may be of great aid for a system of social control. Its contribution to the system's effectiveness is dependent, however, on the uniformity of the effect of a given behavior, no matter who performs it, and on the uniformity with which a sanction tends to reter or encourage it. Kvutza goals and conditions result in a high degree of both kinds of uniformity in regard to the norms mentioned. Since the uniform effectiveness of kvutza public opinion as a sanction has already been discussed, our discussion will now concentrate on uniformity of effect of a given behavior.

Kvutza members want their society to survive and be productive. They have set up an economic system which requires diligent and cooperative work by all if it is to succeed. Any behavior which is cleemed non-cliligent and which does not appear to contribute to the required coordination of effort will be viewed as threatening loss to kvutza productivity. Such behavior would include failure to work at one's top ability and to comply with one's work assignment; failure in these respects would be interpreted as causing loss to the kvutza. Similarly, anyone who receives more than an equal share in food, clothes, or housing is threatening the goal of a "just society" and subjecting the other members to "relative deprivation." "While variations in the other direction-too much work or substandard consumption-are less of a cause for concern, they also seem to be a source of disturbance, perhaps because vicarious experience makes such behavior unpleasant to those who observe it. Whatever the reasons, strict compliance with these norms is generally considered desirable, while violation of them is typically viewed as a loss to the members as a whole.

One of the greatest weaknesses of kvutza controls arises from failure to specify the identity and special privileges of the high-prestige members. ${ }^{\text {st }}$ Managers and old-timers are distinguished in fact from the ordinary workers

22. For development and use of this concept, see 1, 2 The Amerucan Solumex (Stouffer, ed. 1949).

23. See the discussion of this stratum in Rosenfeld, Social Stratification in a "Classless" Society, 16 AMr. Soc. Rev. 766 (1951). The picture given there is very similar to that observed in the kvutza studied, except for Rosenfeld's observations on the attitudes of the different strata toward institutional change. 
and "simpletons" in the deference shown them and, within narrow limits, in the preference they may receive in housing. furniture, travel, and education for their children. Deviations from the general norms by the "important" people are less disturbing than if performed ly ordinary members, since kvutza public opinion recognizes their special worth and power. But difficulties sometimes arise from uncertainty as to how important a given individual is and what privileges, if any, are due him.

Such problems tend to be minimized by a denial that important people are treated differently in any way, or that there is in fact a special managerial status. That an equalitarian society should be unwilling to recognize such privileges is not surprising. Material advantages given the important prople are rationalized in terms of the norms and their accepted exceptions. For example, new housing units, built hy the krutza to accommudate an incriated population, were made more elaborate than earlier ones by the inclusion of shower and toilet facilities. These units were designated from the first as "old-timers' housing," and it was explained that the increased age of this group made it difficult for them to use the central facilities. On closer questioning, however, it was revealed that these romms were not intended for other inhabitants who were also advancing in years, namely, a few recent immigrants of middle-age and several resident parents of members. Though the physical need of such persons was at least as great as that of the old-timers, nu one even considered the possibility that they should he given modern accommulations as permanent quarters. Actually the reason was a feeling of injustice that so much be given to people who had done so little for the kvutza, but this was never publicly articulated and the fiction prevailed that the distribution met the requirement of "equal or according to need." Accordingly, the beharior, which was in fact a non-disturbing deviation from the general nurn, was classified as acceptable behavior and was nut negatively sanctioned as were other deviations from the norm.

In most areas, however, norms have been developed which clearly distinguish acceptable from disturbing belavior in a given situation for a clearly delimited category of persons. Ambiguities which arise are usually brought before the General Assembly and are conclusively resolved by its decisiun. Sometimes the kvutza reaches a consensus informally. The resultant norms are applied with a high degree of certainty. Though for our purposes the reasons need not be spelled out, it would appear that krutza norms can be unambiguous and simple because behavioral alternatives and variations are sharply limited and because a homogenous population is in general agreement in distinguishing desirable from undesirable behavior among these clear and limited alternatives.

Moshav norms, by contrast, are far less explicit, uniformly applied, or generally agreed upon. While it is important that a farmer manage his own holdings effectively and be a good neighbor, the exact pattern of actions by which this can be accomplished has never been authoritatively laid down. In most 
areas, the individual is likely to have his own ideas about the proper behavior in a given circumstance. On particular occasions involving the duty to aid one's sick neighbor, cooperation in the use of machinery, and a member's violation of State ration controls, widespread difference of opinion was discerned among moshav members. This difference was partly attributed to the influence on each member of such factors as the effect of the particular behavior on his own economic interest; his relations with the actor in question: and his conception of the responsibility owed to the moshav by its members.

Such crucial questions as property relations in the family and between neighbors are still being deliberated and moshav members vary widely in their views on such matters. The problem of succession is just beginning to arise with regularity, and its importance and difficulty for a village with limited, indivisible and inalienable farmsteads may hardly be over-estimated. Perhaps a uniform set of norms will be evolved over a period of time to deal with such problems, or perhaps the problems, especially concerning property, defy informal concensus. At any rate, for the present, there is little agreement. It is small wonder, then, that the moshav system of informal controls has been supplemented by a specialized group of deliberators able to make norms and to ensure their sanction by legal means.

\section{The Effects of Prior Experience}

Those who perceive pertinent behavior and are able to apply effective sanctions must do so frequently, vigorously, and speedily. The likelihood that they will is dependent on past experiences with these and alternative reactions. A given sanction is likely to be so applied at a given time if it has previously been followed by gain and if competing reactions lave not. The relative gain which has previously followed a given sanction is a function, at that earlier time, of the optimality of norms ${ }^{24}$ and the capacity of the sanction to impose the impact needed. Sanction impact, in turn, depends on information, implementation, magnitude of gain or loss, and vicarious learning at that earlier time, and on the then extant reaction tenclencies. Reaction tendencies depend in turn on preceding experience and therefore on all the other factors mentioned as they existed at a still earlier period. Thus, the impact of a given sanction is dependent on its previous impact, in a way which renders the entire history of that sanction significant for the understanding of a current control system. To summarize this formally: the impact of a particular sanction, being affected by frequency, vigor, and speed with which it is applied, is an increasing function of the reactors' previous experiences of gain following the use of this sanction in similar situations, and a decreasing function of the reactors' previous experiences of gain following the use of competing reactions in similar situations.

24. An optimal norm is defined as one which produces the maximum reduction of disturbance. 


\section{Tendency tou'ard Informal Sanction:}

As far as could be ascertained, the conditions which promoted effective informal control existed from the first or arose early in the history of the kvutza. Since it started out as a small settlement with a homogeneous population, it was, if anything, even more of a primary group during its formative years than at present. There is sufficient evidence in reports of old-timers to indicate that pertinent behavior was readily perceived, that public opinion was an easily implemented and effective sanction, and that unambiguous norms defined the circumstances under which such sanctions should be employed. There were, to be sure, instances where these controls failed to work, as for example in regard to the use of spending money. An early norm permitted each member to take as much money from a common fund as he felt he needed for personal expenses. In practice this is said to have resulted in low expenditures by the "idealistic" members and disproportionately high ones by those with a weaker sense of social responsibility. When public opinion proved incapable of controlling this socially disturbing behavior, the General Assembly modified the norm to stipulate a yearly amount for each member's personal use. Clarification of the distinction between acceptable and disturbing behavior in this area permitted the effective application of negative sanction to the latter, with the result that few members exceeded their allotted amount thereafter. The desired result was achieved by changes which increased the effectiveness of informal sanction rather than substituting legal controls for them.

Because effective informal control was achieved in the kvutza, the tendency for its subsequent use was increased. That this tendency was high is indicated not only by the many successful instances of its use, but perhaps even more by the persistence with which it was employed on the rare occasions when it failed. Most striking among the illustrations of this is the case of a woman who was considered by the entire kvutza to be anti-social. Soon after her arrival she began to behave very aggressively, quarreling with all her fellow: workers in the kitchen and even striking them. Though the use of violence against a fellow member was shocking to the other members, only the usual mild sanctions were at first applied. For some reason, however, social disapproval failed to deter the woman. She continued the same course of behavior through seven years, during which she was subjected to more vigorous informal controls and was at the same time denied formal membership. But she was never subjected to force, expulsion, or even to material disadvantage. Only during her eighth year in the kvutza was a different type of sanction directed against her: she was given no work assignment and was deprived of the opportunity to work for the kvutza. After a year in which her isolation was thus increased, she bowed to the pressure and left the kvutza. Whether the new sanction be designated informal or legal, it is clear that it was an alternative to the traditional informal sanctions of public opinion. That it was employed only after seven years of persistent exercise of the traditional sanctions is striking indication of the firmness with which the latter were established. 
In the moshav, the tendency to exercise informal controls seems much less powerful. This is not surprising in view of previously described conditions which would minimize the effectiveness of such sanctions. Though these conditions are described as existing at the time of the study, they are traceable to the economic structure of the moshav, and thus it is reasonable to assume that they also existed at the inauguration of the community. If so, they preceded the rise of legal controls which evolved gradually during the first twenty years of the settlement's history. During this period and subsequently, informal controls have regularly been tried, but have been ineffective, presumably because of inadequate information, implementation, sanction magnitude, and norms. In the course of time, members have learned that informal controls are ineffective; the resultant lowered tendency to invoke these controls, resulting in even less frequent and less vigorous attempts to use them, has further diminished their effectiveness. ${ }^{25}$ This attitude toward informal controls was exemplified by moshav reaction to the prank of a group of adolescents who raided a melon patch and openly ate the stolen melons. Indignation ran high because the melons had been specially cultivated for the wedding feast to be given in honor of the marriage of the farmer's datughter. Failing action by the Judiciary Committee, the feeling prevailed that there was "nothing at all to do" about it. Said one member, "If you scold those fellows, they laugh at you." So on the informal level, no serious attempt was undertaken to exert effective control.

\section{Competing Reaction Tendencies:}

Infrequent and non-vigorous exertion of informal sanctions in the moshav may result in part from the competition of legal controls as an effective alternative. It is, of course, impossible to explain the original occurrence of legal controls in these terms, but once they had become established, their success as a competing reaction could have been expected to reduce the impact of informal sanctions. Within the kvutza, there was no comparable history of legal controls which might have constituted a competing alternative to the prevailing system. Free from such competition, ${ }^{20}$ the impact of informal sanctions could have been expected to continue without abatement.

25. This appears to be an instance of what has been described as the "self-fulfilling prophecy," Mertox, Social Theoky aNd Social Strlcture 179-95 (1949), although the "prophecy" is here taken not as the independent variable, but simply as a reflection of previous failure and low tendency.

20. Another type of competition comes from other reactions which typically exert neither legal nor informal controls and may therefore be designated non-control reactions. Amongst these, two of particular interest are withdrawal from interaction and modification of values. In the kvutza, withdrawal from interaction is very difficult except through emigration. As we have seen, this occurs more frequently in the kvutza than in the moshav. If anything, by removing those individuals who were disposed toward noncontrol reactions, informal controls were strengthened and not weakened. On the other liand, kvutza members often meet disturbance by a modification of values. Some behavior which is initially thought likely to cause social loss-e.g., demand for individual radios-not 


\section{CONCLUSION}

Several factors have been discussed with reference to their effect on social control. The kvutza was characterized by a number of conditions which, our theory suggests, engender a more effective informal control system. Presence of these factors, and the effective controls which they produced, was interpreted as a partial explanation for the failure of the kvutza to develop a legal control system. By contrast, the moshav did not possess these characteristics to the same degree as did the kvutza and accordingly failed to develop an effective informal control system. The development of legal institutions in the moshav is partially explicable in these terms. Law has thus been seen to develop where disturbing behavior occurred which was not as adequately controlled informally as it could be with the aid of legal controls. If a similar process exists in the United States, its accurate description should contribute to the prediction and evaluation of our own legislative and judicial decisions.

infrequently comes to be accepted as socially gainiul. In any event, since they are usually in competition with both informal and legal controls, the strength of such nun-control reactions as modification of values and withdrawal from interaction generally fails tu explain the form of control in a given community. 


\section{THE YALE LAW JOURNAL}

\section{EDITORIAL BOARD}

DAvid R. HYDE

Editor-in-Chief

\author{
Richard A. Siegal \\ Article and \\ Book Review Editor
}

Marvin Katz

David R. TILLINGHaSt

JoN R. WALTZ

Note and Comment Editors

WilliaM BaronofF

Robert WM. Berend

RICHARD K. Berg

MuRry David Brochin

BARRY R. BRYAN

Thomas N. Carruthers, Jr.

Jerome A. Cohen

Donald J. Coen

LEwIS G. COLE

John W. Colleran

William H. Denspey, Jr.

Russeil. C. Dilks

David A. Drexler

S. GORDON ElKINS

KLAUS EPPLER
JOSEPH M. FIELD

BERNARD FINKELSTEIX

JOSEPH B. GILDENHORN

Alan Gladstone

Howard Alan Glickstein

Norman S. Goldsmith

Harold Grabino

ANNe Gross

Charles S. Haight, Jk.

Elliot Lee Hoffmas

ALEXANDER P. HoffmanN

ROBERT L. LASKY

Noet Arnol.d Levin

Charles S. Mechent, Jr.

Thomas F. Netson

\section{Payson WolfF \\ Managing Editor}

Stuate M. PAley

Alvin H. Scirvlat八N

JeANNe Ritchie SHo'ek

MonRoe SilverMian

Richard S. Simmons

Daniel M. Singen

Gordon B. Spivack

Melvin Stein

David R. TOLL

STEPHEN W. TUliN

Gerald WaLpin

Roger A. WELCH

PaUl R. Weltchek

Harold M. Wit

George C. ZachakY

MARJE McMaton

Business Secretary

\section{CONTRIBUTORS TO THIS ISSUE}

Allison W. Brown, JR. A.B. 1947, Antioch College; LL.B. 1950, University of Michigan. Member of the District of Columbia Bar.

Richard D. Schwartz. B.A. 1947, Ph.D. 1951, Yale University. Instructor in Sociology, Yale College; Research Fellow in Behavior Science, Institute of Human Relations, Yale University. 